\title{
P2P 类型非法集资案件的法律分析和对策--以草根投资为例
}

\author{
陈宇超
}

华东政法大学

DOI:10.32629/ej.v2i6.287

[摘 要] 涉及众多出借人的P2P兑付违约案件司法处理的难点主要在于非法集资与合法网络借贷的性质界定以及刑事定性后出现具体处理上 的刑民交叉现象。 $\mathrm{P} 2 \mathrm{P}$ 行业出现的重大挫折, 有监管不到位、立法空白、 $\mathrm{P} 2 \mathrm{P}$ 公司违法犯罪等诸多因素所导致。我们宜摒弃在处理民刑交叉案件 中重刑事轻民事的传统, 以财产价值最大化的原则处理众多的涉案财产, 尽量减少在这场失败的互联网金融创新中最大的受害者出借人的实际 损失。通过对 “草根” 的案情解剖, 涉及法律关系分析, 以及后续的财产处分建议, 有助于给司法实践中如何解决 $\mathrm{P} 2 \mathrm{P}$ 类型的案件提供一定的参考 价值。

[关键词] 非法集资; P2P；草根；刑民交叉；衡平

\section{1 案情简介}

草根投资是浙江草根网络科技有限公司运营的 $\mathrm{P} 2 \mathrm{P}$ 平台, 草根投资成 立之初就因其号称拥有上市公司、风投公司、国资背景和明星公司作为股 东的显赫背景而广受关注。2015年, 草根获得顺为资本A轮千万美元投资; 2016年, 获得广州汇垠沃丰10亿元人民币的B轮融资；2017, 获得上市公司 华闻传媒1亿元C轮融资。2018年7月31日草根投资暴雷。

浙江草根网络科技有限公司是草根投资的运营主体, 目前股东有金忠 栲认缴金额11336.16(56.1\%)，拉萨经济技术开发区顺盈投资有限公司 708. 52 (3.51\%), 拉萨美格投资合伙企业 (有限合伙) 3700 (18.31\%), 广州汇 垠沃丰投资合伙企业 (有限合伙) $4255.32(21.06 \%$ )，山南华闻创业投资有 限公司207. 8652 (1. 03\%)。通过对浙江草根网络科技有限公司股权结构的 梳理, 发现法人金忠栲实现了对该公司的绝对控股。其对外宣传的显赫背 景, 只是美化公司, 欺骗投资者的一种手段。

从事后复盘来看, 这种手段在临近暴雷期更为疯狂。“草根” 在 2018 年 6 月 4 日, 官网上发布草根投资获 23 亿元D轮融资, 由上市公司洲际油气 (600759) 领投, 洲际油气下设产业基金基金及众多老股东参与跟投的消 息。随即，“草根” 进一步扬言欲借壳登陆港股。7月12日, 港股上市公司 汇银国际发布公告称草根投资创始人金忠栲出任汇银国际行政总裁, 加入 董事局。事实上, 在不到一个半月以后, “草根” 即宣告暴雷, 这些信息纯 属假新闻。草根接连发布这些虚假信息的真实目的是以 “上市在即” 为由 头, 群发信息给投资人, 并且配以年化 $15.6 \%$ 的高收益诱骗投资者跟投。这 期间 “草根” 还向投资者发放现金或实物奖励, 净增投资350万元以上者,

3. 4加强档案管理信息化建设

事业单位档案管理工作中涵盖的内容较多, 且随着社会的发展、科技 技术的完善, 档案管理工作的内容仍在逐渐增加, 传统档案管理模式已经 无法适应现今工作需求, 有必要参照现今实况, 加大信息技术的应用, 构建 信息化管理体系, 更好的推动档案管理工作的开展,彻底改进档案管理工 作质量。另外, 在实际档案管理工作中, 引进更多先进技术, 在确保档案信 息准确性的前提下, 延长档案保存时间。

此外, 事业单位应对档案管理信息化建设进行创新, 创新中需要注意 的内容有: 一是要求档案管理人员要加强自身能力, 注重信息把握的准确 性、有效性, 加快信息传输速度; 二是加大先进设备及技术的引进力度, 实现信息化档案管理系统的构建。并要求档案管理人员及时将收集到的资 料数据录入到信息系统中来, 且通过先进技术对其实行处理和转化, 生成 数字化数据资料, 提升管理水平, 便于工作人员查询和翻阅。三是建立网络
奖励金额可达 28888 元。在 7 月 25 日, 其在微博官方账号发文称 $D$ 轮融资的 5 亿已经到账。毫无疑问, 这种疯狂的行为是亡命之徒的最后一搏, 而牺牲者 则是广大无喜的投资受害人。

\section{2 “草根”案件涉及法律关系分析}

草根案件案情复杂, 牵涉多种法律关系, 既有民事的, 也有涉及刑事 的。公安机关的介入的标志是实控人金忠栲投案自首, 出于维护社会稳定 和侦查刑事犯罪的多重考量, 公安介入后采取了大包大揽的做法, 将草根 案件的后续处理一手抓。根据草根官网数据显示, 其平台投资总额 861. 894262亿元, 累计为用户赚取20.7952173亿元, 累计注册用户 9042211 人。截至案发, 待还总额约 97.14 亿元, 涉及 13 万出借人。对于此类涉及债 务众多的P2P案件, 其核心可归结为两个界限性问题: (1) p2p案件涉及债务 人众多, 非法集资或网络借贷的界分准则, 通常称为性质边界问题。这个性 质边界本应是行政违法认定与合法网络借贷之间的边界, 但由于现行相关 刑事司法解释规定入罪的数量化门槛相当低, 意味着P2P公司只要出现兑 付困难便必然进入刑事程序, 也可近似视为刑民分野。 ${ }^{[1]}$ (2) 对于P2P公司 已确定进入刑事程序的, 并不一定在其融资发展历史上所涉的全部债务都 是非法集资, 需要在总体定性的基础上从内部对所涉具体个别债务界分刑 事处理的范围。因为 $\mathrm{P} 2 \mathrm{P}$ 公司债务危机的形成有一个自然的时序发展过程, 往往前期可能是正常的借贷, 逐渐出现局部违约, 再进而演变成全面性清 偿危机, 直至被定性为非法集资。在总体定性基础上再从内部界分性质范 围并予以相关的刑民处置。通常称之为内部边界或内部处分问题。

2.1涉及民事实体法部分

管理平台, 公开未设置保密属性的档案资料, 扩充档案管理人员的信息量, 增大档案数据利用率, 以此提高事业单位的服务质量。

\section{4 结语}

综上所述, 事业单位要想真正意义上实现档案的改革, 就需要对档案 管理中存在的问题予以细致分析和理解, 之后结合现有的先进技术, 实现 档案管理的信息化建设, 创新管理理念及方法, 全面完善事业单位档案管 理, 为日常工作的高效开展提供动力和支持。

\section{[参考文献]}

[1]马宇维.事业单位档案管理工作的优化路径探究[J].经济,2016,(8):165.

[2]孙强.事业单位档案管理工作的优化路径探索 [J].现代国企研 究,2016,(22):98.

[3] 阮毅.事业单位档案管理工作的优化路径探究 [J]. 传媒论 坛,2019,2(22):140-141. 
如前所述, P2P线上网络借贷其本质依旧是属于民间借贷。民间借贷在 我国属于合法行为, 《合同法》、《民法通则》及《民通意见》皆有相关的 规定。 ${ }^{[2]}$ 根据最高人民法院《关于人民法院审理借贷案件的若干意见》的 规定指出: “公民之间的借贷纠纷, 公民与法人之间的借贷纠纷以及公民与 其他组织之间的借贷纠纷, 应作为借贷案件受理。” “草根” 作为资金借贷 双方的信息中介所撮合的借贷合同, 理应受到法律的保护, 应当承认合同 有效。“草根”一案中公安机关依据平台数据梳理, 对未还款的 6510 名小额 借款人寄发了催收函, 且组织专案警力抓获涉嫌恶意逃废债的肖某、王某, 对两人采取刑事强制措施, 累计收到大额借款人还款7186万元, 小额还款 1624 万元。这说明, 公安机关在实践中并未认定合同无效, 而是要求资金的 借款方继续按照合同约定及时履行合同的义务。有观点认为: 将 “网络贷 款还原到单个的个人借款合同”, 而网贷平台则是提供居间服务的居间人。 以自然人借款合同和居间合同来解释P $2 \mathrm{P}$ 平台的整体属性有失偏颇, 但是 就认定合同效力来讲并无不妥。根据《合同法》52条及其司法解释有关规 定, 只有违反 “效力性强制规定”, 合同才属无效。效力性强制规定, 通常 指 “法律、行政法规明确规定违反了这些禁止性规定将导致合同无效或者 合同不成立; 或者虽然法律、行政法规没有明确规定违反这些禁止性规范 后将导致合同无效或者不成立, 但是如果违反了这些禁止性规范的合同继 续履行, 将损害国家利益或者社会公共利益的规范”。 ${ }^{[3]}$

现阶段涉嫌违法犯罪P 2 P网贷公司, 其触及罪名通常为“非法吸收公众 存款罪” 和 “集资诈骗罪”。刑法属于强制性规范, 但是刑法对涉及这两种 罪名的行为的否定性评价的目的是 “违反国家金融管理法律规定, 干扰正 常金融秩序”。刑法并没有否定 $\mathrm{P} 2 \mathrm{P}$ 公司在运营中, 促成的出借人与借款人 所签订的借款合同本身。刑法和民法的行为效力选择并非必须始终保持一 致, 两者既可以统一也可以对立, 刑法对非法吸收公众存款犯罪行为的否 定性评价重点在于对违反或扰乱国家金融管理秩序行为的否定评价, 而不 是对双方当事人合意借贷的效力评价。 ${ }^{[4]}$ 依据民事法律的标准, 其注重双 方意思表达的真实性。P2P公司本身涉嫌违法并不影响个别借贷合同的真 实有效, 如果一律将其效力性持否定态度, 有违刑法的楼抑性原则。况且, 如果将借款合同认定无效, 则犯罪人实质上免除了合同约定的利息义务, 借款人也可以合同无效为由拒绝继续履行合同。这不利于出借人合法利益 的保护, 更是会导致犯罪人和违约人因为自己的不守法行为而获利。

综上所述, “草根” 案件中的借贷合同应属于我国《合同法》第54条 规定的可变更可撤销合同。《合同法解释 (二) 》第14条对《合同法》第52 条第5项项规定中的强制性规定解释为效力性强制性规定, 并不因为 “草 根” 的犯罪行为, 导致借款合同的无效。借款合同的定立没有违反法律、 行政法规效力性的强制性规定。效力上采取从宽认定, 是该司法解释的本 意, 也可在最大程度上尊重当事人的意思自治。可撤销合同的民事效力取 决于被欺计一方的补充意思表示。

\section{2 涉及刑事实体法部分}

余杭警方发布《通报 (十一)》, 以依法对犯罪嫌疑人金某某、宗某某 等 27 人, 分别以涉嫌集资计骗罪、非法吸收公众存款罪移送余杭区人民检 察院起诉。根据通报所涉及的罪名, “草根” 案件是作为非法集资类型案 件进行司法处理的。我国《刑法》没有直接使用 “非法集资罪” 作为一个 规范的罪名, 这一名词是被广泛适用于司法解释中, 如 2010 年最高院发布 的《关于审理非法集资刑事案件具体应用法律若干问题的解释》(简称《解 释》)。“非法集资” 应当说是 “非法吸收公众存款罪” 和 “集资诈骗罪” 的总称。

根据《刑法》第一百七十六条规定, 非法吸收公众存款罪是指违反国 家金融管理法规非法吸收公众存款或变相吸收公众存款, 扰乱金融秩序的
行为。准确理解非法吸收公众存款罪的关键在于首先要坚持该罪的行为主 体的不特定性和危害金融秩序的具体性统一。《解释》第一条具体定义“非 法吸收公众存款罪” 构成的四个要件 “未经有关部门依法批准或者借用合 法经营的形式吸收资金”、“向社会公开宣传”、“承诺还本付息”、“向社会 公众即不特定对象吸收资金”。将这四个要件并列, 即 “非吸” 罪名的构成 必须同时符合这四个要件。“草根” 是否符合这四个要件, 我们可以进行比 对。首先, 想当然由于 “草根” 案件涉及人数众多, 且公司公开存在六年持 续宣传因而符合其中的第二和第四要件。

“草根”的经营许可证载明允许其从事第二类增值电信业务中的信息 服务业务, 即通过公共网络基础设施提供有偿信息服务。P $2 \mathrm{P}$ 公司主要从事 的网络借贷业务, 平台本身即是通过提供信息服务促成借贷双方交易发 生。 ${ }^{[4]}$ 有关部门没有批准 “草根” 从事金融业务, 但是在其公司的运营中 其明显实质使用了金融工具。草根” 在其官网上公开承诺: “全部理财项 目 $100 \%$ 本息保障。草根投资承诺所有理财产品 $100 \%$ 本息保障, 一旦借款人 出现任何形式的逾期, 坏账, 草根投资会收回相关债权, 优先保证所有草根 投资人的本金及利息。” 显然, 草根实质性的使用了金融工具 “存款”。存 款作为一种金融工具, 其在金融学的本质上是一种信用工具。以信用为媒 介进行的交易是基于对交易对方未来支付能力与意愿的信任，它有别于以 货币为媒介的商品交易。《刑法》第176条中所使用的 “存款” 概念应当严 格符合金融学对存款的定义。存款的本质即是银行或其他合法金融机构基 于自身信用, 承诺还本付息吸收公众存款的重要金融工具。显然, “草根” 在其从事业务过程中符合《解释》的第一要件和第四要件。同时《解释》 第三条规定了追究刑事责任的标准, 以草根涉案金额之巨, 涉及人数之多, 以远超规定的入刑门槛。因而， “草根” 及其实控人和相关人员以 “非法 吸收公众存款罪”追究刑责, 符合法律规定。

另一涉及的罪名是集资计骗罪。该罪与 “非吸” 的最主要区别是 “以 非法占有为目的”。根据《刑法》第一百九十二条规定, 集资计骗罪是指以 非法占有为目的, 违反有关金融法律、法规的规定, 使用诈骗方法进行非法 集资, 扰乱国家正常金融秩序, 侵犯公私财产所有权, 且数额较大的行为。 “草根”触犯这个罪名, 应当是在其明知资金链即将断裂的情况下, 仍谎称 即将赴香港上市, 获得上市公司融资等, 诱导出借人加大投资的行为, 这在 文章第一部分已有论述。根据《解释》第四条规定, 集资诈骗罪中中的非 法占有目的, 应当区分情形进行具体认定。行为人部分非法集资行为具有 非法占有目的的, 对该部分非法集资行为所涉集资款以集资诈骗罪定罪处 罚。故而, “草根” 案件在司法的处理中应严格确定时间点来区分集资计 骗所涉及的金额本数。

\section{3 统一于衡平原则的财产处分}

处理一起整体上确定进入刑事处理程序的 $\mathrm{P} 2 \mathrm{P}$ 案件, 司法实务上最为 艰难的要点在于如何认定合法网络借贷和非法集资刑事犯罪间的区隔, 重 点则在于后续财产的处分。“草根” 案件在进入刑事处理后, 涉案各方关联 人之间利益格局和法律地位发生了深刻变化。本来诸多出借人共同指向 “草根”平台要求其还本付息的利益诉求变成了诸多出借人之间的互相联 动的格局。一是形成众多出借人之间利益交错, 零和博弯的平面格局; 二 是会出现代表全体出借人利益的整体利益; 三是由于P2P案件的爆发产生 外部效应, 例如牵涉上市公司、房地产项目和借款公司。这样就形成了一 个特殊的平面多层多维的利益结构。我们必须有针对性地考虑在P2P案件 特殊的利益结构中寻求特别的处置方法以期平衡各方利益, 实现法律的衡 平原则。

3. 1 执行程序根据查封财产特点采取价值最大化措施 要平衡各方利益诉求的经济基础是已经冻结查封的资产, 因而将冻结 